\title{
Deoxidation of Molten Steel with Deoxidizer
}

\section{Containing Aluminum*}

\author{
By Koichi ASANO** and Taketo NAKANO***
}

\section{Synopsis}

The mechanism of deoxidation of molten steel with deoxidizer containing aluminum was investigated in an induction furnace.

The results obtained are summarized as follows.

(1) Shape of deoxidation products in molten steel is cluster after addition of aluminum or $\mathrm{Al}-\mathrm{Mg}-\mathrm{Si}$, and is globular after addition of $\mathrm{Al}-\mathrm{Ca}-$ $\mathrm{Si}-\mathrm{Mn}$.

(2) Though cluster type deoxidation product appears to consist of isolated particles in a two-dimensional image, it is a single body in which the particles join together in the three-dimensional configuration.

(3) Deoxidation products after addition of aluminum or $\mathrm{Al}-\mathrm{Mg}-\mathrm{Si}$ are big size of clusters and float up in molten steel very rapidly. But deoxidation products after addition of $\mathrm{Al}-\mathrm{Ca}-\mathrm{Si}-\mathrm{Mn}$ are small size of isolated globular products. Consequently, the rate of decrease of total oxygen content in molten steel is much faster with the addition of aluminum or $\mathrm{Al}-\mathrm{Mg}-\mathrm{Si}$ than with that of $\mathrm{Al}-\mathrm{Ca}-\mathrm{Si}-\mathrm{Mn}$.

\section{Introduction}

Deoxidation in steelmaking is a very important process; its success or failure governs largely the quality of product steel. In order to obtain "clean steel," it is a major problem for engineers engaged in steelmaking how to remove the deoxidation products from steel after deoxidation.

Many studies ${ }^{1-13)}$ have been made in this field from early days. For example, in connection with change of oxygen content in the steel after addition of deoxidizer, those reports are related to the reactions with deoxidizer, ${ }^{10)}$ to the adsorption of deoxidation products into refractories, ${ }^{9)}$ and to the floatation of the deoxidation products in the steel. ${ }^{3,6)}$

In the present study, investigations have been made on the behavior of deoxidation of molten steel with deoxidizer containing aluminum.

\section{Deoxidizers}

The deoxidizers used were metallic aluminum, Al$\mathrm{Mg}-\mathrm{Si}$ and $\mathrm{Al}-\mathrm{Ca}-\mathrm{Si}-\mathrm{Mn}$ alloys. Their appearances are shown in Photo. 1, and the chemical compositions in Table 1. Aluminum and $\mathrm{Al}-\mathrm{Ca}-\mathrm{Si}-\mathrm{Mn}$ are in

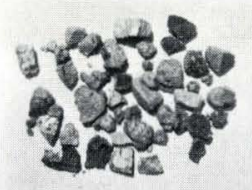

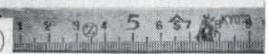

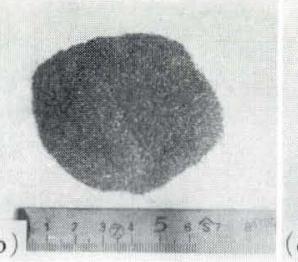

1

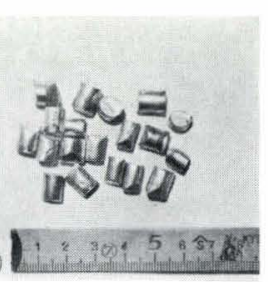

massive form of the size about $10 \mathrm{~mm}$, and $\mathrm{Al}-\mathrm{Mg}-\mathrm{Si}$ is powder.

\section{Experimental Procedure}

The experimental furnace used is schematically shown in Fig. 1. Low carbon steel of $40 \mathrm{~kg}$ was melted by induction heating and held at $1600^{\circ} \mathrm{C}$ in a magnesia crucible of internal diameter $170 \mathrm{~mm}$ and depth $370 \mathrm{~mm}$ under argon atmosphere. The oxygen content in the argon atmosphere was about $0.5 \mathrm{vol} \%$. And the carbon content in the molten steel was $0.20 \%$ when the deoxidizer was added.

Each deoxidizer added was $0.1 \mathrm{wt} \%$ as aluminum to the molten steel. Thus, the amount added was $0.62 \mathrm{wt}^{\mathrm{O}} \%$ for $\mathrm{Al}-\mathrm{Mg}-\mathrm{Si}$ and $0.22 \mathrm{wt}^{\circ} \%$ for $\mathrm{Al}-\mathrm{Ca}-\mathrm{Si}-$ $\mathrm{Mn}$. A given amount of deoxidizer was wrapped in steel wire gauze, which was then fastened to an iron rod, and added to the molten steel at $1600^{\circ} \mathrm{C}$. Addition of aluminum or $\mathrm{Al}-\mathrm{Ca}-\mathrm{Si}-\mathrm{Mn}$ was at a time;

Table 1. Chemical composition of deoxidizers (wt $\%$ )

\begin{tabular}{l|cccccc}
\hline Deoxidizers & $\mathrm{Al}$ & $\mathrm{Ca}$ & $\mathrm{Mg}$ & $\mathrm{Si}$ & $\mathrm{Mn}$ & $\mathrm{Fe}$ \\
\hline $\mathrm{Al}-\mathrm{Ca}-\mathrm{Si}-\mathrm{Mn}$ & 44.9 & 14.9 & - & 8.0 & 29.7 & - \\
\cline { 1 - 2 } $\mathrm{Al}-\mathrm{Mg}-\mathrm{Si}$ & 16.1 & - & 21.1 & 50.7 & - & 11.1 \\
$\mathrm{Al}$ & 99.9 & - & - & - & - & -
\end{tabular}

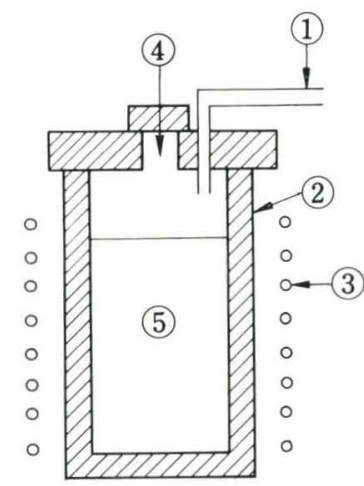

(1) Argon inlet tube

(2) Magnesia crucible

(3) High frequency induction coil

(4) Handling hole for addition of deoxidizer, sampling, and temperature measurement

(5) Molten steel

Fig. 1. Schematic drawing of experimental furnace

Photo. 1.

Deoxidizers

(a) $\mathrm{Al}-\mathrm{Ca}-\mathrm{Si}-\mathrm{Mn}$

$\begin{array}{ll}\text { (b) } \mathrm{Al}-\mathrm{Mg}-\mathrm{Si} & \text { (c) } \mathrm{Al}\end{array}$

* Originally published in Tetst-to-Hagané, 57 (1971), 1943, in Japanese. English version received March 1, 1972.

** Hirohata Works, Nippon Steel Corp., Hirohata-ku, Himeji 671-11.

*** Formerly Hirohata Works, Nippon Steel Corp., now at Product Research and Development Laboratories, Nippon Steel Corp., Fuchinobe, Sagamihara 229. 
and $\mathrm{Al}-\mathrm{Mg}-\mathrm{Si}$ was divided in eight parts and added successively. After each addition of the deoxidizer, samples were taken from the molten steel at a given intervals with a steel ladle of inside diameter $24 \mathrm{~mm}$ and then quenched into water.

\section{Results}

\section{Total Oxygen Content in the Molten Steel}

The changes of total oxygen content, determined by vacuum fusion method, are shown in Fig. 2. The rate of decrease of the total oxygen content in the molten steel after addition of the deoxidizer is the largest in the case with $\mathrm{Al}-\mathrm{Mg}-\mathrm{Si}$, followed by aluminum, and the smallest with $\mathrm{Al}-\mathrm{Ca}-\mathrm{Si}-\mathrm{Mn}$.

\section{Deoxidation Products in the Molten Steel}

\section{i. Shape and Structure of Deoxidation Products}

Samples taken from the molten steel after addition of the deoxidizer were polished, and the deoxidation products were observed through an optical microscope. Photograph 2 shows typical examples of these products. The deoxidation products with $\mathrm{Al}-\mathrm{Ca}-\mathrm{Si}-$ Mn are largely globular, and occasionally small cluster as shown in Photo. 2 (a 2). Gn the other hand, the deoxidation products with aluminum or $\mathrm{Al}-\mathrm{Mg}-\mathrm{Si}$ form large cluster in large number right after addition of deoxidizer, while they rapidly disappeared from the steel with the time, leaving behind the tiny grains as shown in Photos. 2 (b 2) and (c 2).

Examples of the deoxidation products identified by

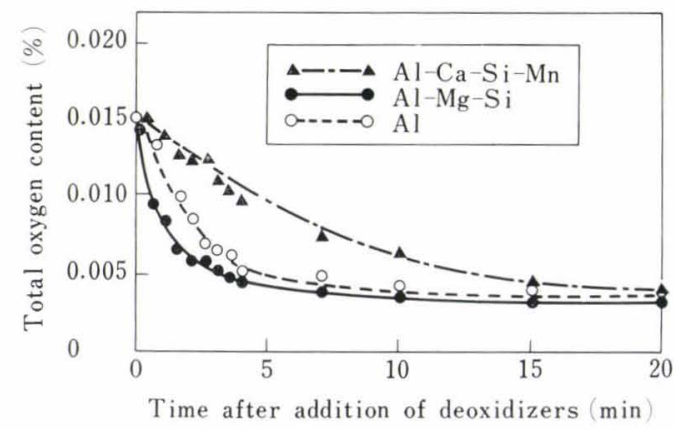

Fig. 2. Change of total oxygen content in molten steel after addition of deoxidizers electron probe microanalyser (EPMA) are shown in Photo. 3. The deoxidation product in cluster form, since the particles observed on a polished plane were small, was exhibited in X-ray image. It was found that the globular deoxidation products formed by deoxidation with $\mathrm{Al}-\mathrm{Ca}-\mathrm{Si}-\mathrm{Mn}$ were mainly the oxides

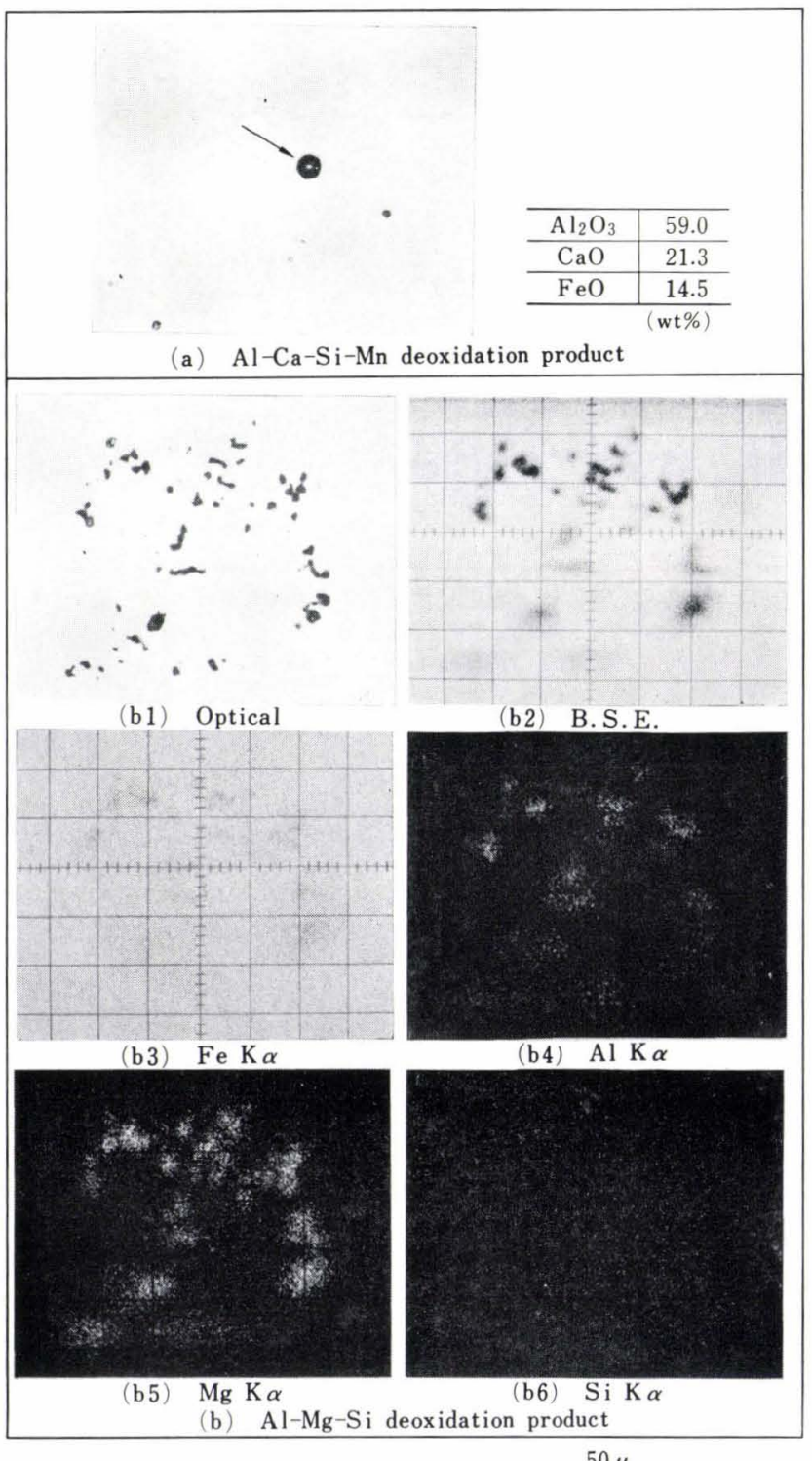

$50 \mu$

Photo. 3. Identification of deoxidation products by EPMA

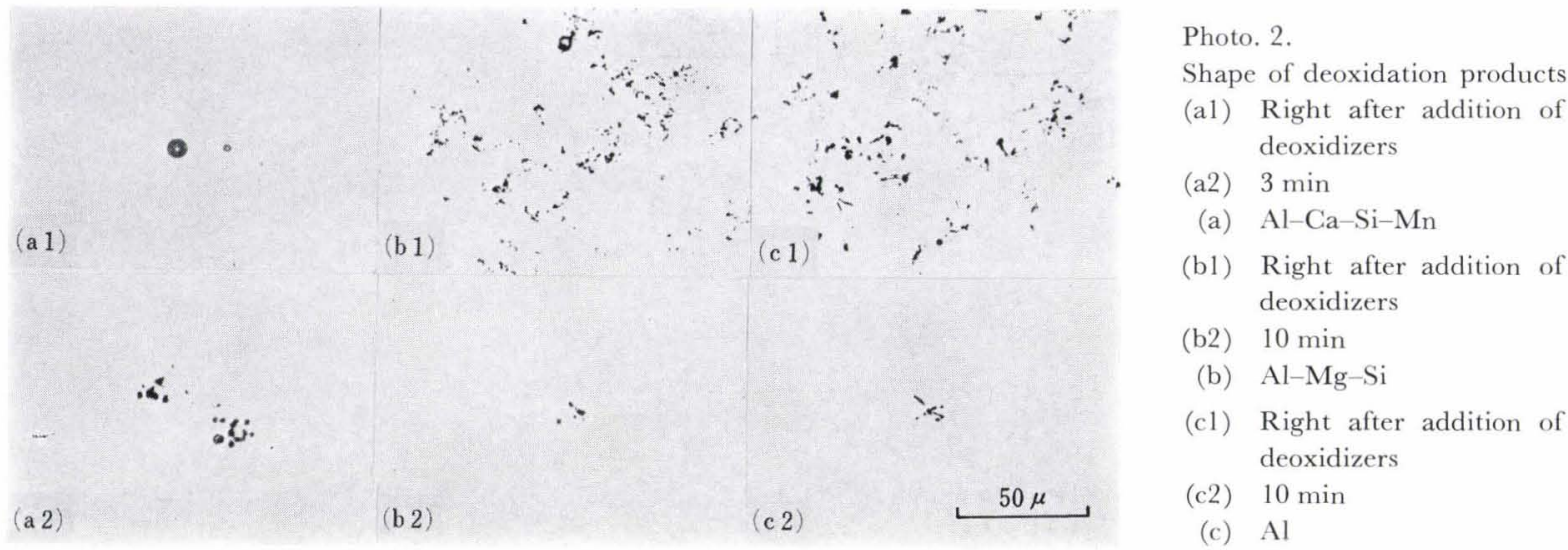


of aluminum and calcium, and the clusters with $\mathrm{Al}-$ $\mathrm{Mg}-\mathrm{Si}$ were mainly the oxides of aluminum and magnesium.

\section{ii. Size and Number of Particles in the Deoxidation Products}

The size and the number of particles in the deoxidation products were measured through the optical microscope with 400 magnifications at each 100 fields on the respective samples. The results obtained are shown in Fig. 3.

From these results, the following equation was derived for the relation between particle size $D_{p}(\mu)$ and the number of particles of this size $\mathcal{N}\left(D_{p}\right)$ :

$$
\mathcal{N}\left(D_{p}\right)=\mathcal{N}_{0} \cdot \exp \left(-f \cdot D_{p}\right)
$$

where,

$D_{p}:$ size of the particles $(\mu)$

$\mathcal{N}\left(D_{p}\right)$ : the number of particles of size $D_{p}(\mu)$ No and $f$ : constants.

The sizes of individual particles were mostly less than $10 \mu$ in all the deoxidation products. Among them deoxidation product particles with $\mathrm{Al}-\mathrm{Ca}-\mathrm{Si}-\mathrm{Mn}$ were the largest.

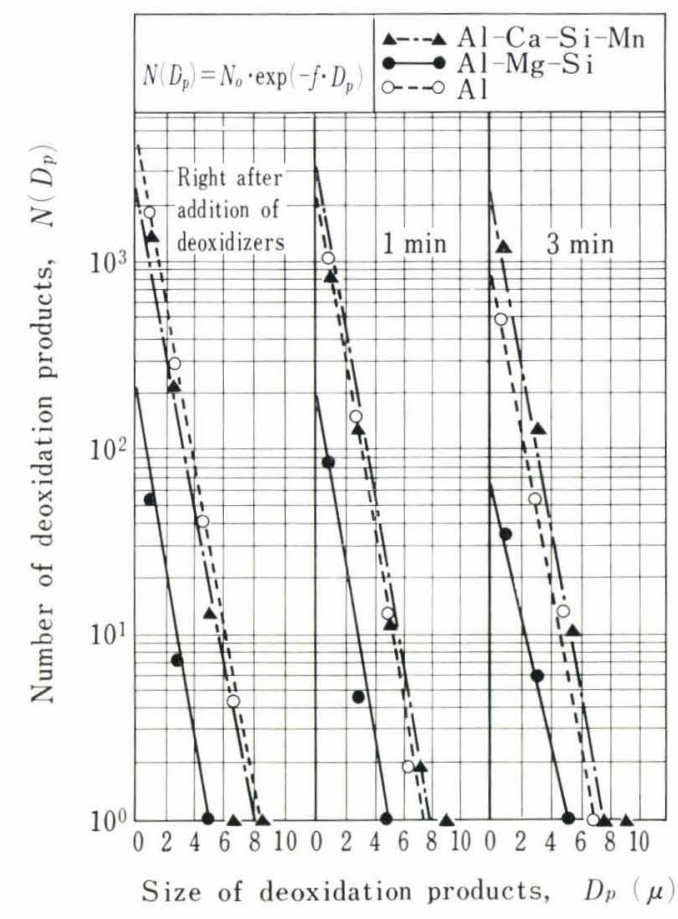

Fig. 3. Size distribution of deoxidation products

$$
D_{c}=\frac{D_{1}+D_{2}}{2}
$$
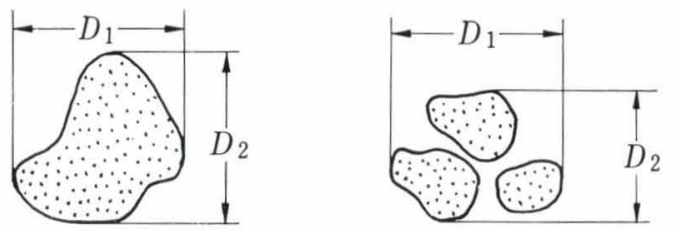

Fig. 4. Decision of cluster size $\left(D_{c}\right)$

\section{iii. Size and Number of the Cluster Deoxidation Prod-} ucts

In order to better understand the change in clusters with time, described in (i), the size and numbers of clusters were measured on the polished plane of diameter $24 \mathrm{~mm}$ for each specimens. The size of clusters, $D_{c}$, was measured, taking the arithmetical mean of the width and length of a cluster observed on the microscopic field as shown in Fig. 4. The results obtained are shown in Fig. 5.

In the case of deoxidation with aluminum or $\mathrm{Al}-$ $\mathrm{Mg}-\mathrm{Si}$, the clusters of fairly large size came out right after addition of the deoxidizer. However, they disappeared rapidly with the passage of time. Then, in the deoxidation with $\mathrm{Al}-\mathrm{Ca}-\mathrm{Si}-\mathrm{Mn}$, the deoxidation products were mostly globular, with no clusters of large size such as in the other two cases. The sizes of small clusters were below $100 \mu$, as shown in Photo. 2(a 2).

\section{Discussion}

1. Floating Velocity of Cluster Deoxidation Product in the Molten Steel

Total oxygen content in the molten steel after addition of the deoxidizer decreases very much differently, depending upon the nature of each deoxidizer, as already pointed out by many workers. ${ }^{1-4,8,10)}$ Since it was disclosed by the authors, ${ }^{13)}$ as shown in Fig. 6, that the amount of dissolved oxygen in molten steel decreases rapidly after addition of a deoxidizer, it

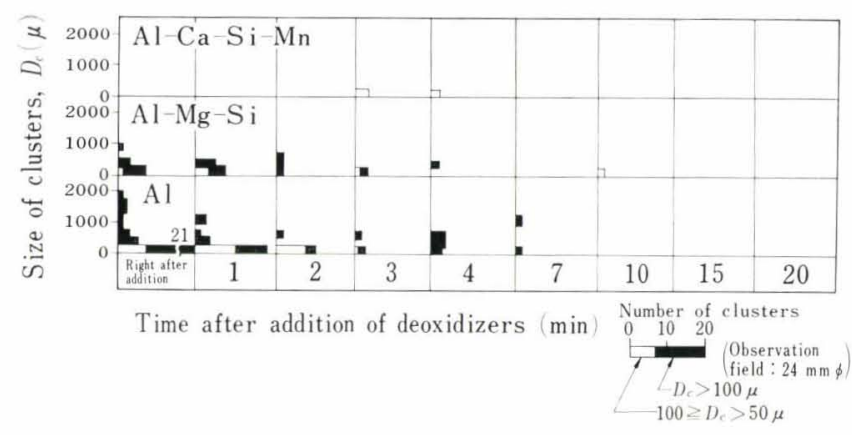

Fig. 5. Change of size and number of clusters over $50 \mu$ after addition of deoxidizers

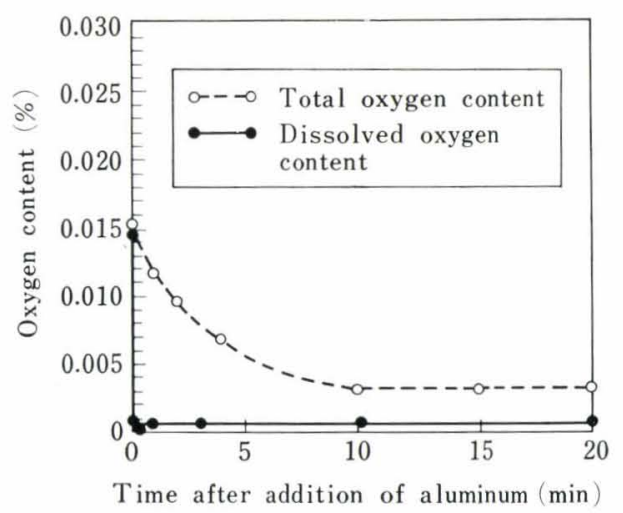

Fig. 6. Change of dissolved oxygen and total oxygen contents in molten steel after addition of $0.3 \%$ aluminum $^{13}$ 


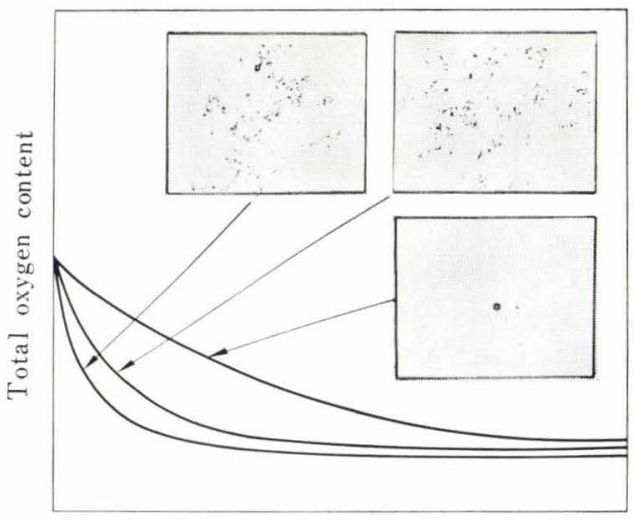

Time after addition of deoxidizers

Fig. 7. Shape of deoxidation products and change of total oxygen content in molten steel after addition of deoxidizers

might be considered that the oxygen exists mostly as deoxidation products in steel deoxidized with a deoxidizer. Consequently, the difference of total oxygen content in the molten steel after deoxidation with different deoxidizer may be caused by the corresponding difference to floating velocities of each deoxidation products.

Figure 7 shows the change of total oxygen content in the molten steel with the passage of time in the present study. It is seen in the figure that the clusters, though the constituent particles are small in size, float up rapidly, possibly due to their large size.

The floating velocity of the deoxidation product through still molten steel, v, can be expressed by Eqs. (2), (3), or $(4),{ }^{14) *}$ under an assumption that the shape of these products is globular:

Stokes region $(R e \leqq 2)$

$$
v=\frac{10^{-8} \cdot g \cdot\left(\rho-\rho_{p}\right)}{18 \cdot \mu} \cdot D_{p}^{2}
$$

Intermediate region $\left(2 \leqq R e \leqq 5 \times 10^{2}\right)$

$$
v=\frac{4.10 \times 10^{-6} \cdot g^{5 / 7} \cdot\left(\rho-\rho_{p}\right)^{5 / 7}}{\rho^{2 / 7} \cdot \mu^{8 / 7}} \cdot D_{p}^{8 / 7}
$$

Newton region $\left(5 \times 10^{2} \leqq R e \leqq 2 \times 10^{5}\right)$

$$
v=\frac{1.74 \times 10^{-2} \cdot g^{1 / 2} \cdot\left(\rho-\rho_{p}\right)^{1 / 2}}{\rho^{1 / 2}} \cdot D_{p}^{1 / 2}
$$

where,

Re: Reynolds number $\left(=\rho v D_{p} / \mu \times 10^{4}\right)$

$v$ : floating velocity of the deoxidation product $(\mathrm{cm} / \mathrm{sec})$

$g$ : gravitational acceleration $\left(\mathrm{cm} / \mathrm{sec}^{2}\right)$

$\rho:$ density of the molten steel $\left(\mathrm{g} / \mathrm{cm}^{3}\right)$

$\rho_{p}:$ density of the deoxidation product $\left(\mathrm{g} / \mathrm{cm}^{3}\right)$

$\mu: \quad$ viscosity of the molten steel $(\mathrm{g} / \mathrm{cm} \cdot \mathrm{sec})$

$D_{p}$ : size of the deoxidation product $(\mu)$.

Then, representing $D_{p}$ at the boundary of Stokes and intermediate regions, at the boundary of inter-

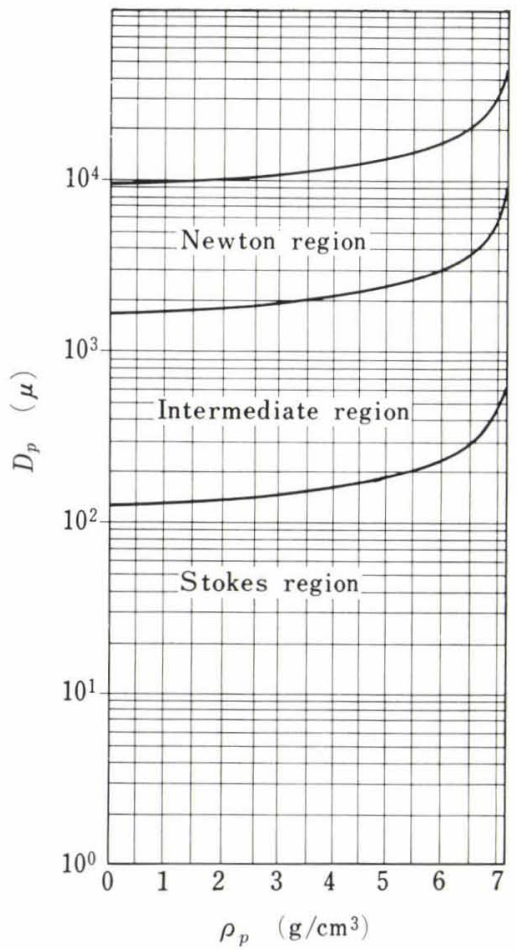

Fig. 8. Boundaries of Stokes, intermediate, and Newton regions calculated from density $\left(\rho_{p}\right)$ and size $\left(D_{p}\right)$ of deoxidation products

mediate and Newton regions and at the upper limit of Newton region by $D_{P S I}(\mu), D_{P I N}(\mu)$, and $D_{P N M}(\mu)$, respectively,

$$
\begin{aligned}
& D_{P S I}=3.3 \times 10^{4}\left(\frac{\mu^{2}}{g \cdot \rho \cdot\left(\rho-\rho_{p}\right)}\right)^{1 / 3} \cdots \\
& D_{P I N}=43.5 \times 10^{4}\left(\frac{\mu^{2}}{g \cdot \rho \cdot\left(\rho-\rho_{p}\right)}\right)^{1 / 3} \cdots \\
& D_{P N M}=2364 \times 10^{4}\left(\frac{\mu^{2}}{g \cdot \rho \cdot\left(\rho-\rho_{p}\right)}\right)^{1 / 3}
\end{aligned}
$$

The relation of $\rho_{p}$ with $D_{P S I}, D_{P I N}$, and $D_{P N M}$ is shown in Fig. 8, where $g=980 \mathrm{~cm} / \mathrm{sec}^{2}, \rho=7.1 \mathrm{~g} / \mathrm{cm}^{3}$, and $\mu$ $=0.05 \mathrm{~g} / \mathrm{cm} \cdot \mathrm{sec}^{\left..{ }^{15}\right)}$ It is seen that the deoxidation product of $\rho_{p}=3.0 \mathrm{~g} / \mathrm{cm}^{3}$, for example, is in the Stokes region as far as its size is smaller than about $150 \mu$.

The relation among the size of deoxidation product, its density and the floating velocity, taking into consideration of critical sizes in (5), (6), and (7), as revealed from Eqs. (2) to (4), is shown in Fig. 9. It is seen in the figure that even if the density of the deoxidation product, $\rho_{p}$, is somewhat large, the floating velocity of the deoxidation product, $v$, increases rapidly with increase of the size, $D_{p}$. The floating velocity of large clusters as deoxidation product must thus be very high. In fact, the molten steel in an induction furnace is in motion, ${ }^{16)}$ so that the floating velocity in this case will be higher than in still molten steel. ${ }^{1,17)}$ It is, however, difficult to measure its absolute value. Considering that in the present study experiments were made under the same conditions, Eqs. (2) to (4) should be suffi-

* $D_{p}$ is in micron. 


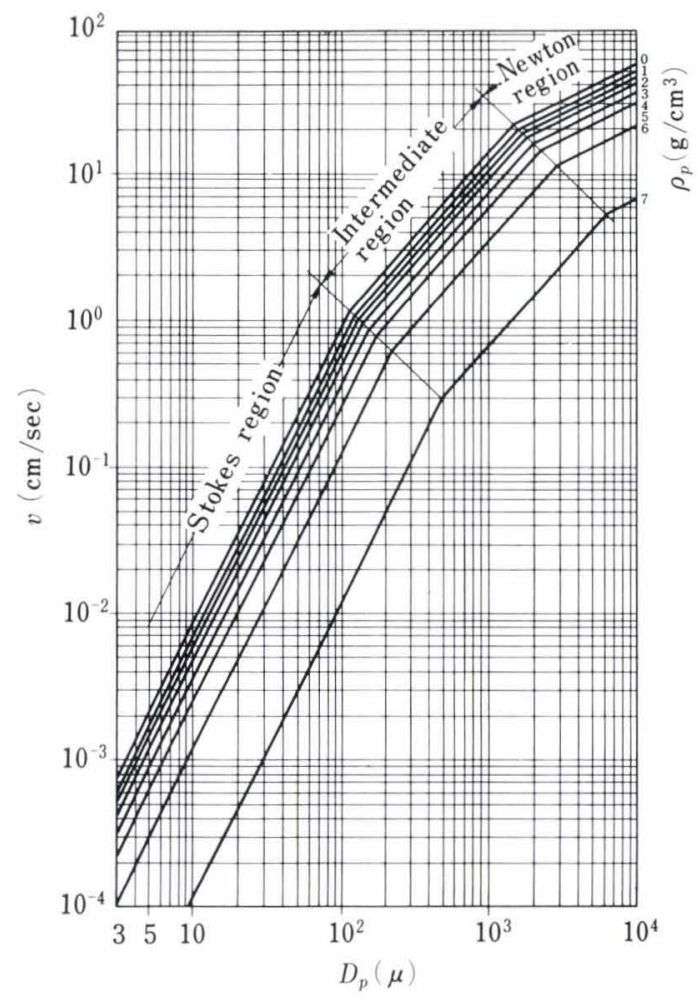

Fig. 9. Floating velocity $(v)$ of deoxidation products as a function of their density $\left(\rho_{p}\right)$ and size $\left(D_{p}\right)$

cient to compare the floating velocities between cluster and globular deoxidation products.

As mentioned above, the deoxidation product with $\mathrm{Al}-\mathrm{Ca}-\mathrm{Si}-\mathrm{Mn}$ was mostly globular, with the size $10 \mu$ at most, and it was mainly the oxides of aluminum and calcium. The density of this globular deoxidation product was not known. However, since the density of oxides in $\mathrm{Al}-\mathrm{Ca}-\mathrm{O}$ systems is about $3.0 \mathrm{~g} / \mathrm{cm}^{3},{ }^{18)}$ the density of the globular deoxidation product can be taken as $\rho_{p}=3.0 \mathrm{~g} / \mathrm{cm}^{3}$. Then, the floating velocity of cluster deoxidation product can be compared with that of globular one, of which size and density are $10 \mu$ and $3.0 \mathrm{~g} / \mathrm{cm}^{3}$, respectively.

In the present case, the floating behavior of the globular deoxidation product is in the Stokes region. Then, the average density of the typical cluster of deoxidation product $\mathrm{Al}_{2} \mathrm{O}_{3}, \rho_{c}$, can be deduced to Eq. (8).

where,

$$
\rho_{c}=\rho \cdot \varepsilon+\rho_{\mathrm{Al}_{2} \mathrm{O}_{3}} \cdot(1-\varepsilon)
$$

$$
\begin{aligned}
\rho_{c}: & \text { density of the } \mathrm{Al}_{2} \mathrm{O}_{3} \text { cluster }\left(\mathrm{g} / \mathrm{cm}^{3}\right) \\
\rho_{\mathrm{Al}_{2} \mathrm{O}_{3}}: & \text { density of } \mathrm{Al}_{2} \mathrm{O}_{3} \text { particle }(=3.99 \\
\left.\mathrm{g} / \mathrm{cm}^{3}\right)^{18)} & \\
\varepsilon: & \text { fraction of steel in the cluster. }
\end{aligned}
$$

The relation among the size of the $\mathrm{Al}_{2} \mathrm{O}_{3}$ cluster, $D_{c}$, and the ratio of floating velocities of cluster and globular deoxidation product, $v_{c} / v_{p}$, calculated based on the Eqs. (2) to (8), is shown in Fig. 10. The value of $1-\varepsilon$ was obtained as 0.03 with an automatic measuring apparatus of Quantimet Image Analysing Computer ${ }^{19)}$ by Metals Research Ltd.

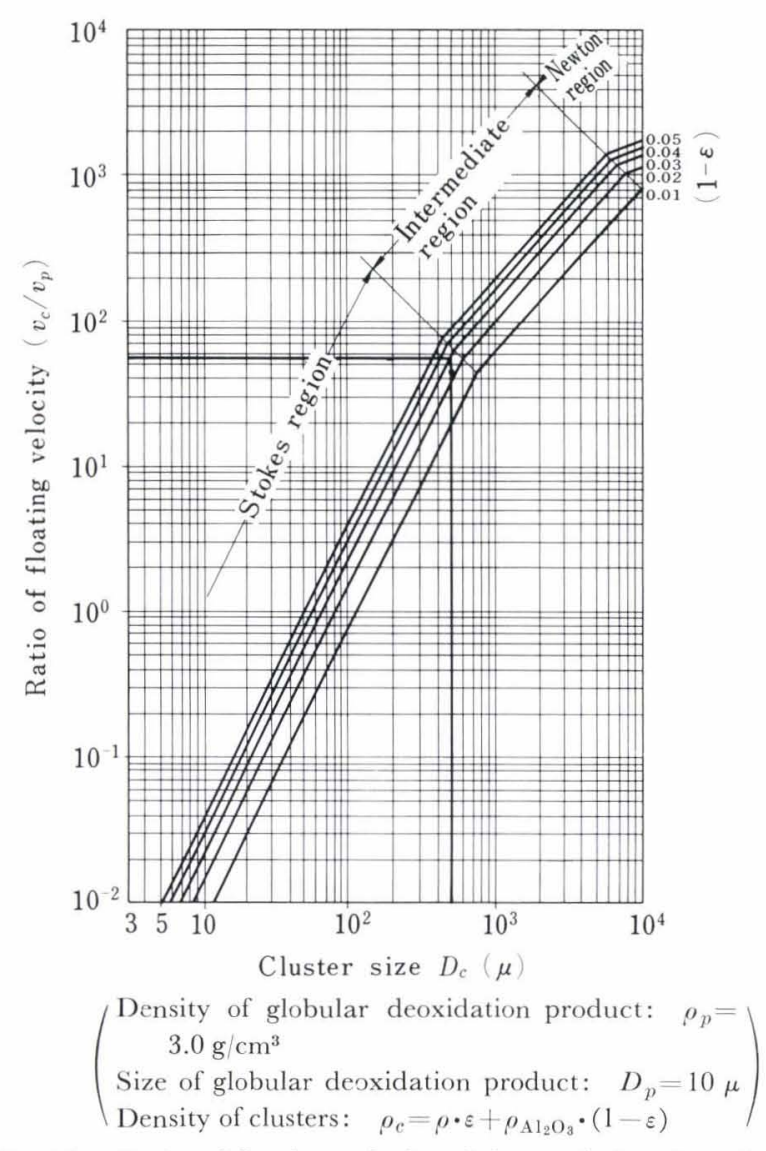

Fig. 10. Ratio of floating velocity of clusters $\left(v_{c}\right)$ to that of globular deoxidation products $\left(v_{p}\right)$

As many clusters of fairly large size, some exceeding even $500 \mu$, are observed among the deoxidation products with aluminum or $\mathrm{Al}-\mathrm{Mg}-\mathrm{Si}$, the floating velocity of the cluster of the size $D_{c}=500 \mu$ is compared with that of the globular deoxidation product of the size $D_{p}=10 \mu$, the maximum size of the globular deoxidation products, with $1-\varepsilon=0.03$ as shown in Fig. 10. It is seen that the cluster deoxidation product floats up about 50 times as fast as the globular deoxidation product. It is thus concluded that when the deoxidation product is in large cluster form after addition of a deoxidizer, its floating velocity is very high, and so the rate of decrease of total oxygen content in the molten steel is also correspondingly high.

\section{Three-dimensional Structure of the Cluster Deoxidation Product}

It is speculated that when the deoxidation product is in cluster form, it does not float up through the molten steel individually in the form of constituting particles, but in the form of assembled cluster with large size. To confirm in this respect, the following procedures were applied.

\section{i. The Stepwise Stripping Observation of the Cluster}

Deoxidation Product

The sample specimen containing cluster deoxidation products was observed through an optical microscope. Then, about 0.5 to $1 \mu$ thickness of the surface from already observed plane was removed by polishing and the same clusters were observed at the fresh surface. The surface was again removed by polishing 


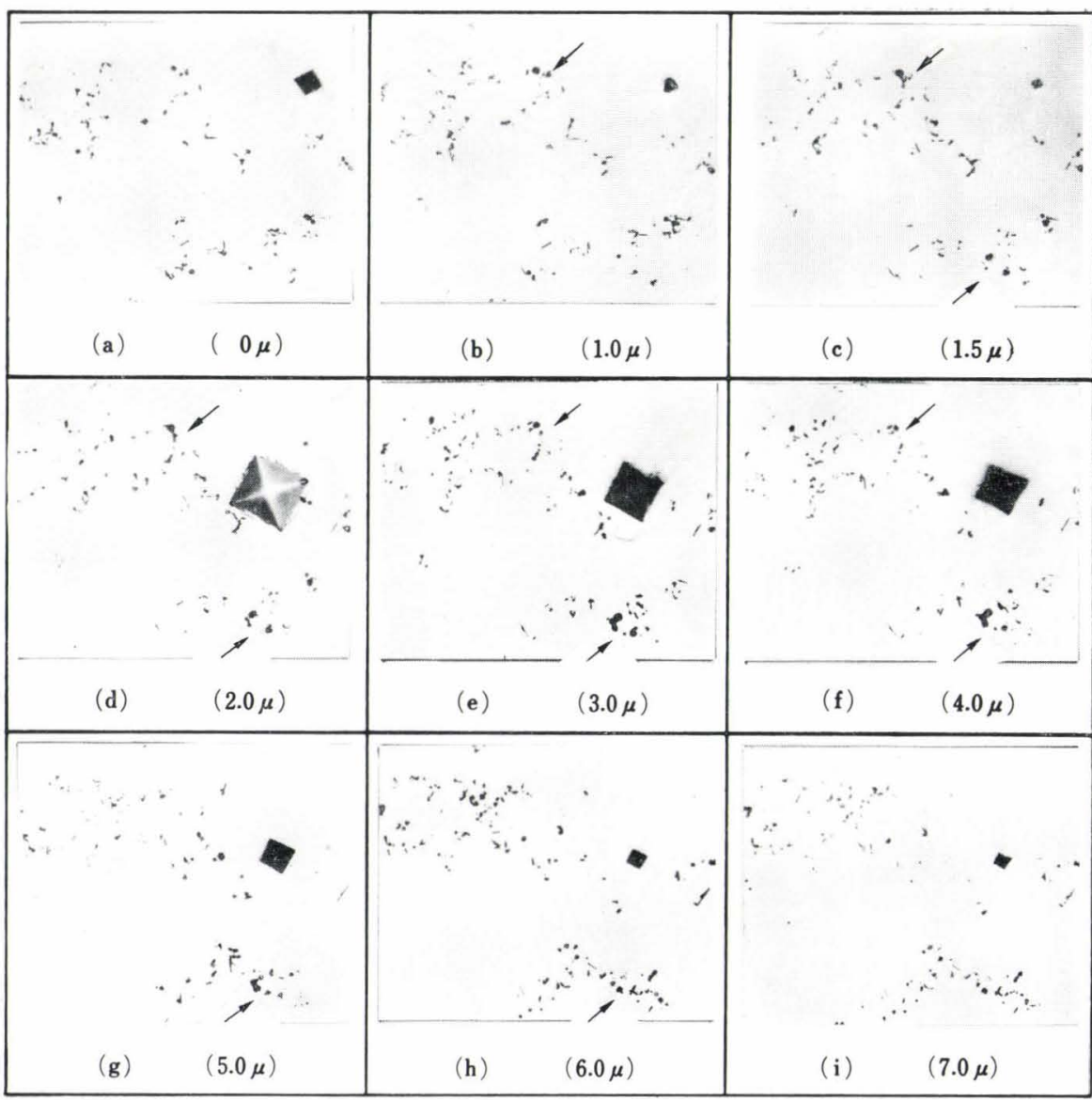

$50 \mu$

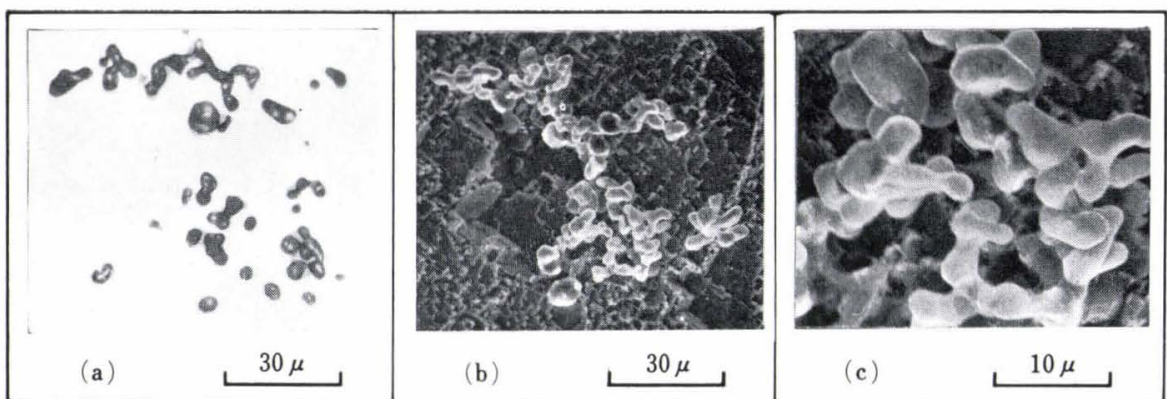

Photo. 4.

Optical microphotographs of cluster type deoxidation products. Numbers in parenthesis show positions of each observed plane as distance from plane " (a) ".
Photo. 5.

Microphotographs of cluster type deoxidation product

(a) Optical microphotograph

(b), (c) Scanning electron microphotograph and observed. In this manner, the repetition of polishing off to expose a new surface and subsequent observation through an optical microscope, the three-dimensional form of cluster deoxidation products was thus pursued. The thickness of the surface removed by polishing at a time was estimated to be 0.5 to $1 \mu$ which was confirmed by calculation after the measurement of diagonal length reductions of the Vickers indentation.

The typical examples are shown in Photo. 4. It is shown in the Photo. 4 that the particles in a cluster deoxidation product appear to be isolated from one another in a two-dimensional image, but, in the threedimensional view, they are joined together as indicated by the arrow mark.

ii. The Observation of the Cluster Deoxidation Product through a Scanning Electron Microscope

The scanning electron microscopes used were JSM-
$\mathrm{U} 2$ and -U3 by Japan Electron Optics Laboratory Co., Ltd.

The sample specimens were taken from the molten steel in the present experiment, and also taken from an aluminum-killed low carbon steel ingot and a steel ingot of SM 50. By polishing and subsequent observation through an optical microscope, the existence of cluster deoxidation products was first confirmed for each specimen. The sample specimen was then etched with $20 \%$ nitric acid solution and the surrounding base iron was removed. The three-dimensional structure of cluster deoxidation products was thus observed through the scanning electron microscope. These observations vividly showed that the particles in a cluster deoxidation product join together and form a single body deoxidation product. The typical examples are shown in Photo. 5.

Consequently, the speculation mentioned above are 
confirmed to be right, that is, a cluster type deoxidation product does not float up through the molten steel in the form of constituent particles, but float up in a single body form.

Reviewing the works $^{1-4,7,8,10)}$ on deoxidation with various deoxidizers, it is evident that the rate of decrease of total oxygen content in the molten steel is larger by deoxidation with aluminum, titanium or zirconium, which forms cluster deoxidation product, than with silicon, calcium, etc., which forms globular deoxidation product.

\section{Conclusions and Summary}

The mechanism of deoxidation of molten steel with aluminum, $\mathrm{Al}-\mathrm{Mg}-\mathrm{Si}$ or $\mathrm{Al}-\mathrm{Ca}-\mathrm{Si}-\mathrm{Mn}$ was investigated in an induction furnace.

The results obtained are summarized as follows.

(1) The shape of deoxidation products in molten steel is cluster after addition of aluminum or $\mathrm{Al}-\mathrm{Mg}$ $\mathrm{Si}$, and is globular after addition of $\mathrm{Al}-\mathrm{Ca}-\mathrm{Si}-\mathrm{Mn}$.

(2) The cluster deoxidation product appears to be of individual particles in the two-dimensional image, but, in the three-dimensional configuration, it is a single body in which the particles join together.

(3) The rate of decrease of total oxygen content in the molten steel is larger by deoxidation with aluminum or $\mathrm{Al}-\mathrm{Mg}-\mathrm{Si}$, than by deoxidation with $\mathrm{Al}-\mathrm{Ca}-$ $\mathrm{Si}-\mathrm{Mn}$. This is because in the former two the deoxidation product is in cluster form of large size, which floats up rapidly in the molten steel.

\section{Acknowledgements}

The authors wish to thank Dr. T. Horigome, Mr. R. Kohno, and Mr. M. Wakabayashi of Product Research and Development Laboratories, Nippon Steel Corporation, for their aid in the observation of cluster deoxidation products through scanning electron microscopes.

\section{REFERENCES}

1) W. A. Fischer and M. Wahlster: Arch. Eisenhüttenw., 28 (1957), 601.

2) E. Plöckinger and R. Rosegger: Stahl u. Eisen, 77 (1957), 701.

3) E. Plöckinger and M. Wahlster: Stahl u. Eisen, 80 (1960), 659 .

4) K. Born: Stahl u. Eisen, 80 (1960), 669

5) Y. Miyashita: Tetsu-to-Hagané, 52 (1966), 1049.

6) M. Kawai, S. Kobayashi, and H. Yonezawa: Tetsu-toHagané, 53 (1967), 336.

7) N. Sano, S. Shiomi, and Y. Matsushita: Tetsu-to-Hagané, 53 (1967), 890.

8) T. Kawawa and M. Okubo: Tetsu-to-Hagané, 53 (1967), 1569.

9) E. Yokoyama and H. Ooi: Tetsu-to-Hagané, 55 (1969), 454.

10) R. Sakagami, C. Kawasaki, I. Suzuki, and K. Sato: Tetsuto-Hagané, 55 (1969), 550.

11) K. Suzuki, S. Ban-ya, and T. Fuwa: Tetsu-to-Hagané, 56 (1970), 20

12) K. Torssell and M. Olette: Rev. Metall., 66 (1969), 813.

13) K. Asano, T. Saeki, and T. Nakano: Proc. ICSTIS, (1971), 584, Suppl. Trans. ISIJ.

14) J.H. Perry: Chemical Engineers' Handbook, (1950), McGraw-Hill Book Co. Inc./Kogaku-sha, Tokyo.

15) K. Nakanishi, T. Saito, and Y. Shiraishi: J. Japan Inst. Metals, 31 (1967), 881.

16) H. Knüppel and F. Oeter: Arch. Eisenhüttenw., 33 (1962), 729.

17) Y. Miyashita: Formation and Removal of Non-metallic Inclusion in Molten Steel, 2nd Nishiyama Memorial Lecture, (1968), ISIJ, Tokyo.

18) K. Narita: Tetsu-to-Hagané, 52 (1966), 1098.

19) C. Fisher and M. Cole: The Microscope, 16 (1968), 81. 